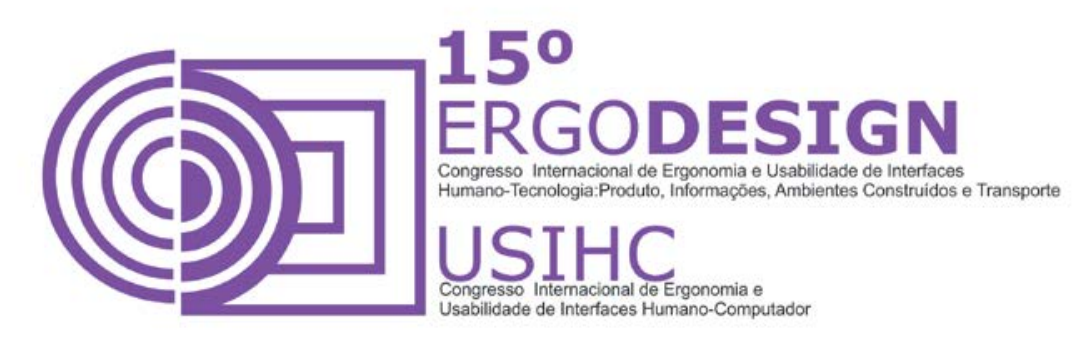

\title{
DIAGNÓSTICO MACROERGONÔMICO DE UMA INDÚSTRIA DE CONFECÇÃO DE VESTUÁRIO
}

\section{MACROERGONOMIC DIAGNOSIS OF AN CLOTHING INDUSTRY}

\author{
ZERBETTO, Cristiane A. de A. (1); NONIS, Sharmila (2)
}

(1) Universidade Estadual de Londrina, Doutora em Agronomia (Energia na Agricultura)

e-mail: cra@uel.br

(2) Universidade Estadual de Londrina, Especialista em Gestão do Design

e-mail: sharmila.n@hotmail.com

\begin{abstract}
RESUMO
Este artigo apresenta uma pesquisa realizada numa confecção de vestuário de moda, onde busca avaliar a estrutura organizacional por meio do método de Análise Macroergonômica do Trabalho (AMT), com objetivo de diagnosticar atributos essenciais para um plano de Gestão de Design, assim como deficiências nos aspectos físicos- ambientais, organizacionais e inter-relacionais, viabilizando soluções.

Palavras-chave: Macroergonomia, Moda, Gestão de Design.
\end{abstract}

\section{ABSTRACT}

This article presents a survey conducted in making fashion garments, which seeks to assess the organizational structure by the method of Macroergonômica Work Analysis (AMT), in order to diagnose essential attributes for a management plan design, as well as deficiencies in aspects of physicalenvironmental, organizational and inter-relational, enabling solutions.

Keywords: macroergonomics, Fashion, Design Management.

\section{INTRODUÇÃO}

O produto de moda pode ser definido como qualquer elemento ou serviço que conjugue as propriedades de criação, design e tendências de Moda, qualidade, conceitual e técnica, ergonômica, estética, apresentação e preço, a partir das vontades e desejos do segmento de mercado para qual o produto foi desenvolvido $(\mathrm{RECH}, 2002)$. Significa a possibilidade da individualidade num grupo e uma relação de status e valores com o ambiente de seus interlocutores, objetivando uma suave 


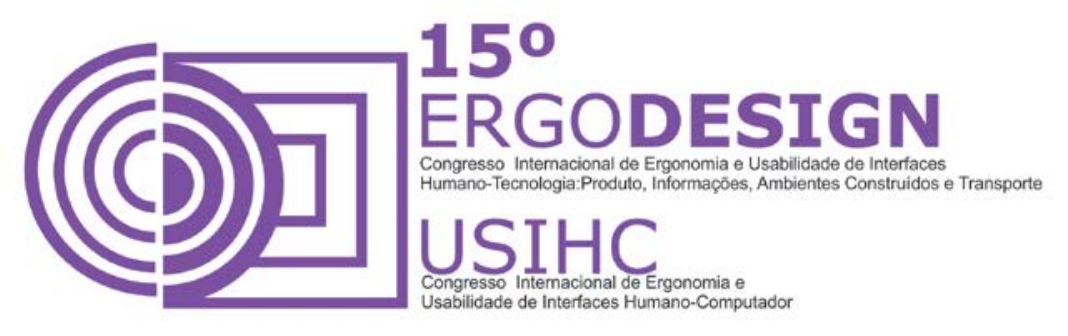

dinâmica entre as relações do sistema indivíduo, roupa, relacionamentos, códigos sociais, na tentativa de um ideal funcionamento (GONÇALVES; LOPES, 2007).

Em 2013, o setor do vestuário teve o maior crescimento nas vendas da indústria paranaense: $28,5 \%$. Foi o terceiro ano de crescimento acelerado do setor, que teve elevação nas vendas de 18,29\%, em 2012, e 17,59\%, em 2011, segundo os Indicadores Conjunturais da Federação das Indústrias do Paraná (FIEP). Hoje, são mais de 2,5 mil fábricas do setor em operação no estado, sendo o quinto maior produtor em volume. A soma dos investimentos bateu a casa dos R $\$ 146,9$ milhões em 2012, com alta de 24,3\% comparada ao ano anterior (FRANCO, 2014).

As regiões norte e nordeste do estado do Paraná concentram a maior parte desta crescente indústria, sendo recentemente chamado de "Corredor da Moda", região que abrange as cidades que ligam Londrina a Cianorte, porém, a cidade de Arapongas, é voltada para o setor moveleiro e apresenta poucas empresas de confecção de vestuário.

Em contribuição com a evolução qualitativa do segmento de confecção, aplica-se a Gestão de Design, que é uma atividade multidisciplinar que atua junto à alta administração da empresa, com o intuito em promover a inovação por meio de métodos estratégicos, motivando os empregados, controlando os trabalhos, cumprindo objetivos, prazos e custos planejados, impulsionando-as à competitividade (WOLF 1998 apud ZERBETTO et al., 2011) por meios de processos operacionais de trabalhos acordados pelo grupo. Quando o Design Estratégico é aliado ao gerenciamento, envolvendo todos os processos, as decisões são tomadas em conjunto e focadas em seus projetos, otimizando tempo (MAGALHÃES 1997 apud ZERBETTO et al., 2011). Com base nesta explanação, pode-se considerar a Ergonomia como importante aliada para a prática da Gestão do Design, visto que, a mesma visa à segurança, satisfação e bem-estar dos trabalhadores, assim como seu relacionamento com o sistema produtivo (IIDA, 2005).

Com base nesta contextualização, propõe-se uma Análise Macroergonômica do Trabalho (AMT) que objetiva detectar os principais Itens de Demanda Ergonômica (IDE's) existentes numa empresa de confecção do vestuário estabelecida em Arapongas, interior do Paraná, por meio de entrevistas e questionários aplicados aos trabalhadores, a fim de propor melhorias físico- ambientais, organizacionais e inter- relacionais.

Deste modo, o método busca relatar por meio da opinião dos trabalhadores em suas respectivas funções, correções coerentes com a sua própria atividade.

A Macroergonomia pode ser compreendida como a Ergonomia dos sistemas, onde o fator principal é a projeção do todo, visto que, é pelo todo que se projetam as partes (subsistemas). O seu propósito é avaliar os quatros subsistemas principais, abrangendo as variáveis ambientais, tecnológicas e interpessoais que interferem nas interações sistêmicas entre os indivíduos e os dispositivos de trabalho, como forma de otimizar a produtividade e organizar o trabalho (BUGLIANI, 2007). Além disso, abrange questões cognitivas que envolvem os processos perceptivos, mental e de motricidade, assim como, as relações interpessoais, visando criar um cooperativismo, diminuindo a competitividade dentro de um grupo (ZERBETTO et al.,2011).

Dessa forma, a participação do usuário proporciona a explicitação de problemas que não são percebidos mediante a simples observação, auxiliando o ergonomista a interpretar e organizar, por meio de pesos de importância, as demandas ergonômicas dos trabalhadores, não se limitando à proposição de mudanças ambientais ou de mobiliário. 


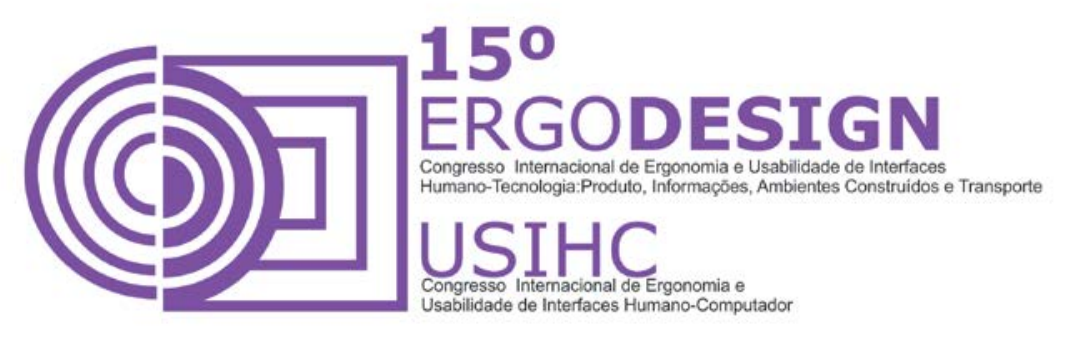

\section{CARACTERÍSTICAS DA EMPRESA}

A empresa analisada está localizada na cidade de Arapongas, no norte do Paraná, e atua no desenvolvimento de produtos do vestuário destinados ao segmento feminino, sendo uma das poucas empresas de confecção encontradas na cidade. Como empresa familiar, iniciou suas atividades em junho de 2013, na casa da proprietária, a partir da observação de oportunidades de mercado e da falta de uma marca na cidade que emprega o conceito de elegância ao estilo casualwear.

Seguindo o princípio de funcionamento dos Ateliês, os produtos são confeccionados artesanalmente, visto que a maioria dos processos são realizados de forma verticalizada, sendo terceirizado apenas o processo de costura. A diferença é que os produtos não são criados sob medida para um cliente específico, eles são produzidos nos tamanhos padrões como $P, M, G$ ou GG, sendo peças únicas em apenas uma numeração, sem grade de produção em série, agregando o aspecto de individualidade ao cliente.

As pesquisas de tendências, desenvolvimento e criação, modelagem, corte são realizados internamente e após o retorno da costura, são feitos os acabamentos em bordado manual, o que agrega o conceito principal da marca. Além disso, todo trabalho de marketing, desenvolvimento, compra de materiais e embalagens de comunicação visual da marca, produção de moda, fotografia e edição são realizados internamente na maioria das vezes.

Os processos citados anteriormente são executados por 2 funcionárias internas em suas próprias residências, sendo o processo de costura terceirizado por facções. A comercialização é feita no showroom da marca, porém $90 \%$ das vendas são realizadas por 3 vendedoras externas independentes, que fazem atendimento personalizado a domicílio na cidade de Arapongas. Dessa forma, não há um horário fixo de trabalho, podendo variar a carga horária de trabalho diário.

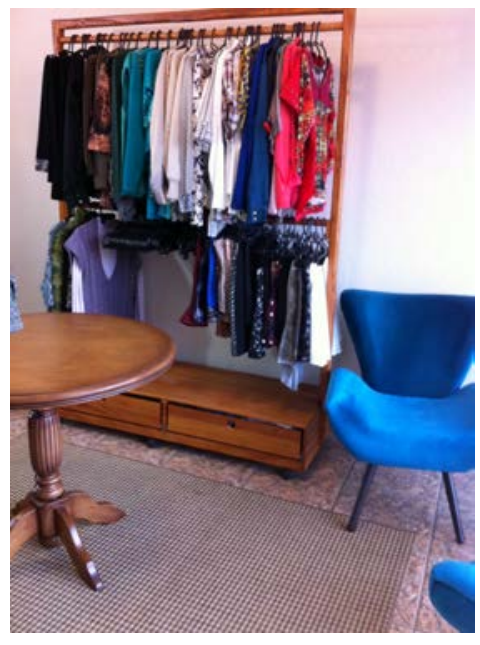

Figura 1- Showroom

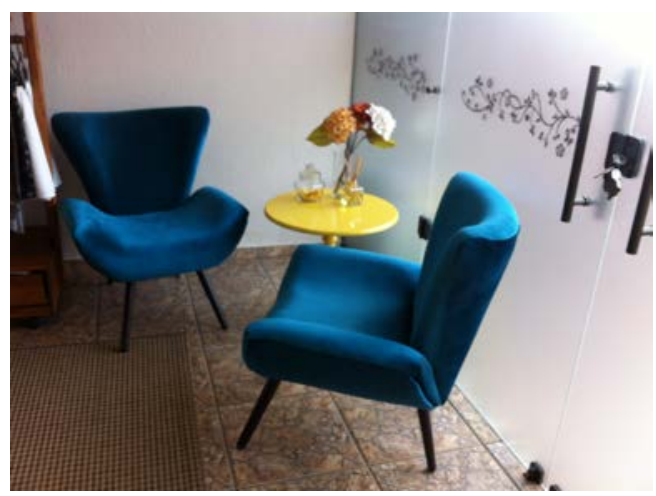

Figura 2- Showroom 

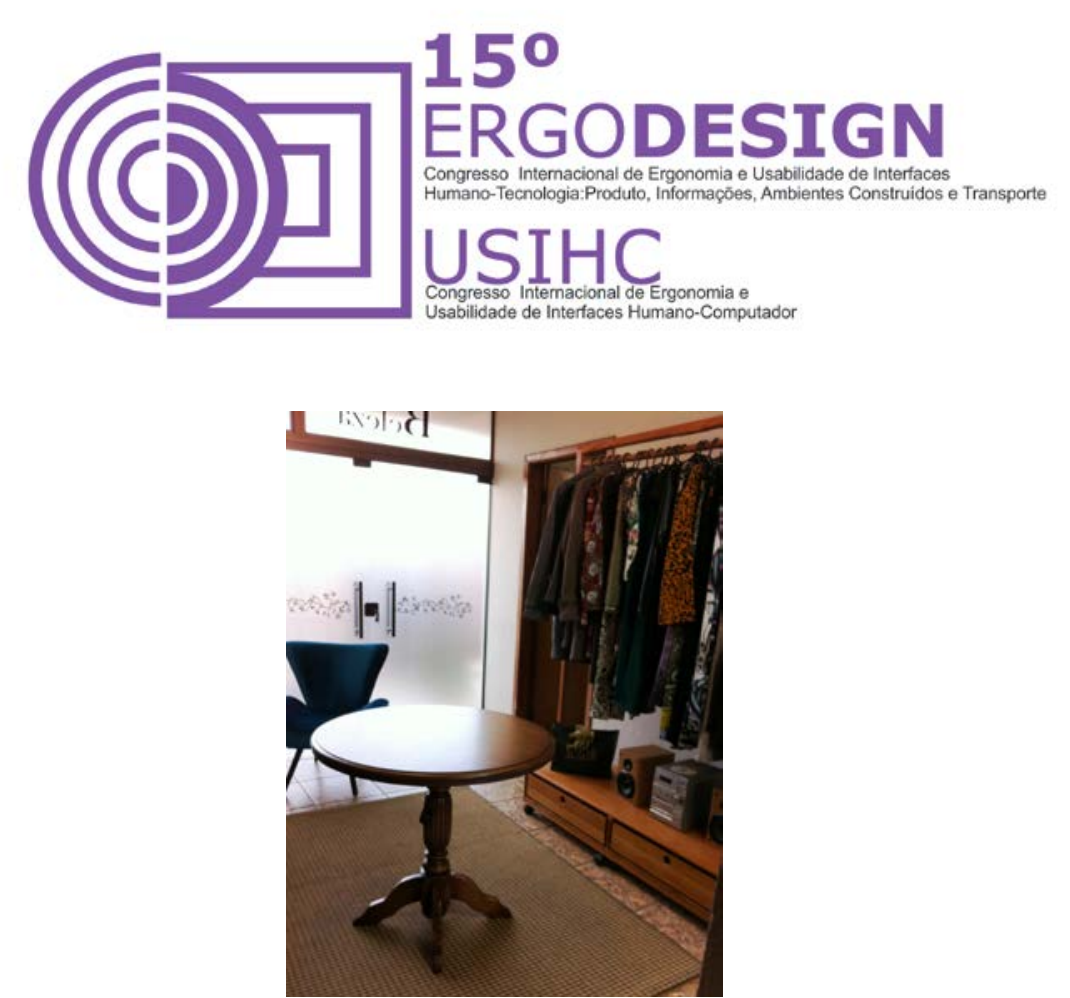

Figura 3- Showroom

A empresa aposta na competitividade por meio de coleções exclusivas, produtos elaborados, elegantes e únicos, da qualidade das matérias-primas utilizadas, do alto padrão de acabamento e de um rigoroso controle de qualidade.

Utiliza como matérias-primas básicas tecidos como viscose, algodão, sarja, viscolycra, couro light, suplex power, paetês, tules, rendas, tricôs, os quais são bordados manualmente com chatons, pedras sintéticas e cristais.

Seu processo produtivo inicia-se com a pesquisa de tendências, compra de tecidos e aviamentos, desenho de criação que posteriormente é transformado em modelagem plana manual. A seguir é feito o encaixe das partes dos moldes no tecido sobre a mesa e posteriormente o corte. A ficha técnica, aviamentos e partes cortadas são encaminhadas para as facções de costura. Quando as peças costuradas retornam para a empresa com a etiqueta interna da marca, é feito uma revisão de costura e acabamento para analisar se está dentro dos padrões de qualidade e uma prova física no corpo para avaliação de modelagem. Caso seja identificado algum problema ou ajuste no corpo é concertado internamente.
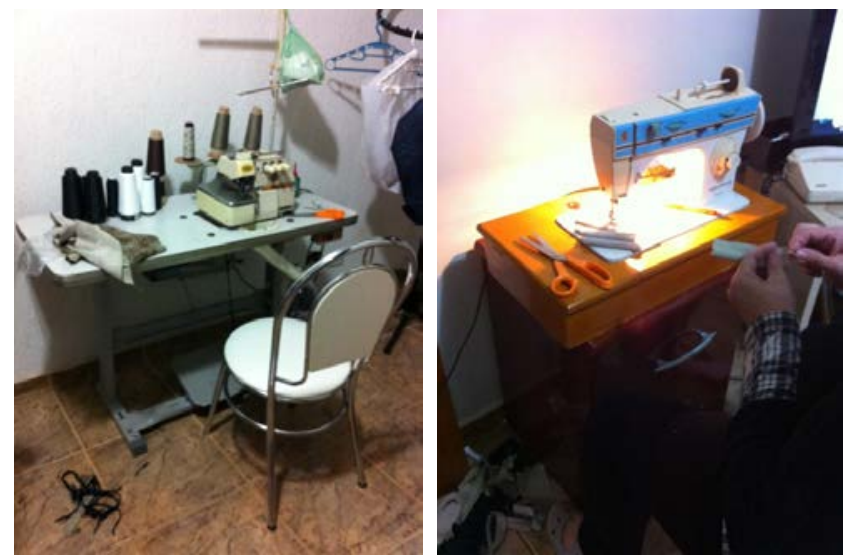

Figura 4- Máquinas Overloque e Reta 


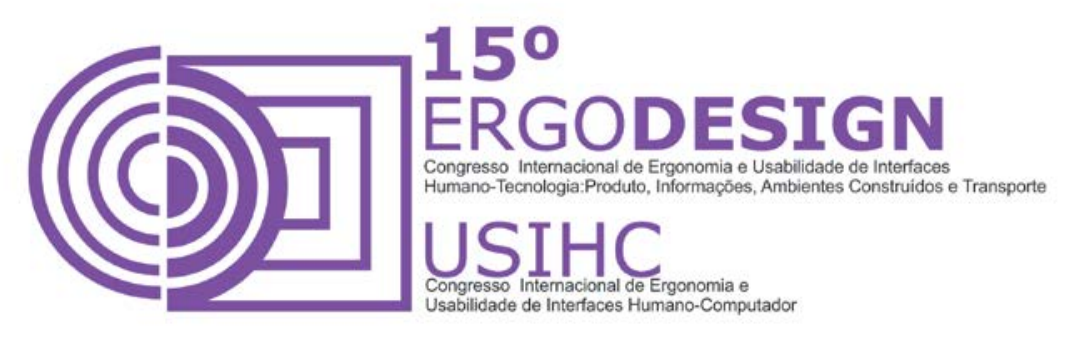

Posteriormente, inicia-se o processo de desenvolvimento do bordado manual onde é definido o desenho ou formato do bordado, a seleção de pedras e linhas que serão utilizadas, para posteriormente iniciar de fato o bordado.

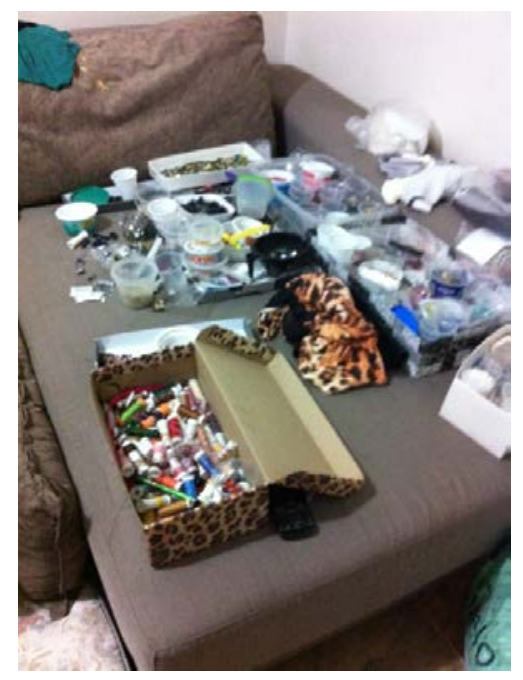

Figura 5- Materiais para bordado

Com base nesta explanação é possível se ter uma ideia geral da empresa e de seu funcionamento.

\section{METODOLOGIA}

O foco deste estudo apresentado é utilizar como método a Análise Macroergonômica do Trabalho (AMT), em que são consideradas as relações dos colaboradores com o posto de trabalho, os quais são fundamentais para apontar as necessidades organizacionais, físicas e pessoais. Este método é inserido na ergonomia participativa onde o colaborador contribui até mesmo para a formulação do questionário, identificando as suas demandas ergonômicas, aumentando a possibilidade de acertos nas sugestões de melhorias que serão propostas.

Segundo Bugliani (2007) esta intervenção ergonômica é dividida em cinco etapas: Apreciação Macroergonômica; Diagnose Macroergonômica; Projetação Macroergonômica; Avaliação, validação e/ou testes ergonômicos; Detalhamento ergonômico e otimização.

Contudo, nesta pesquisa foram aplicadas as três primeiras etapas proposta por Bugliani (2007).

\subsection{Apreciação Macroergonômica}

Essa fase exploratória da pesquisa iniciou-se por meio do mapeamento dos problemas ergonômicos da empresa e da sistematização das tarefas, partindo do princípio do desenvolvimento do produto até sua finalização e disponibilização no ponto de venda, permitindo diagnosticar os IDE'S mais evidentes. 


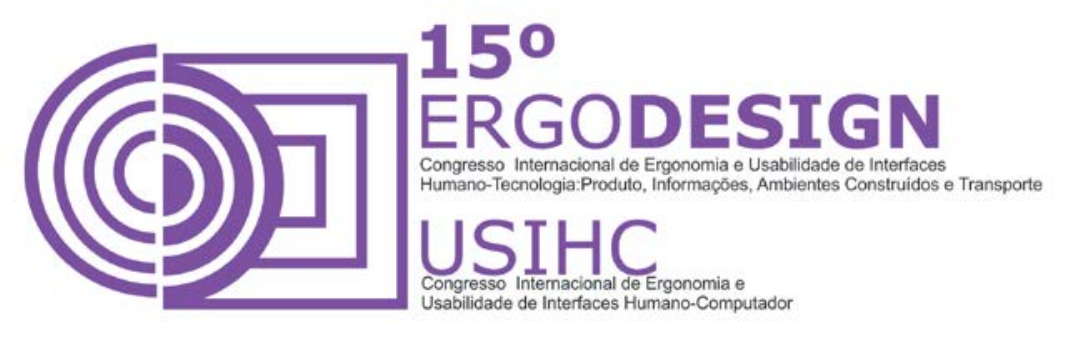

Segundo Moraes e Mont'Alvão essa fase "consiste na sistematização do sistema homem-tarefamáquina e na delimitação dos problemas ergonômicos- posturais, informacionais, acionais, cognitivos, comunicacionais, interacionais, deslocacionais, movimentacionais, operacionais, espaciais, físico ambientais" (2000, p.49).

Nessa fase, foi observado que existem problemas espaciais devido à necessidade de concentração dos equipamentos de trabalho num único espaço, o que otimizaria tempo para executar as devidas funções, sem causar desgaste físico e psicológico.

Também foram detectados problemas ergonômicos-posturais em relação ao tamanho da mesa de corte, necessidade de mesa e cadeira específica para trabalhos como financeiro, criação e desenvolvimento de coleção, entre outros que há necessidade do uso de notebook.

Em segunda instância observou-se que devido a sobrecarga de funções, as colaboradoras não conseguiam focar nas atividades principais, organizar e planejar o que interfere negativamente na produtividade.

\subsection{Diagnose Macroergonômica}

O método permite aprofundar os problemas priorizados pelos colaboradores e testar as hipóteses.

\subsubsection{Entrevista}

Para identificar os IDE's foi realizada uma entrevista sob a visão das 2 funcionárias que realizam a maioria das funções da empresa. Cada colaboradora identificou cinco itens de insatisfação do trabalho, relacionados ao ambiente, posto de trabalho e organização.

Os Itens relatados nas entrevistas foram organizados pela ordem de menção. $O$ primeiro fator mencionado recebeu o peso $1 / 1=1,00$ o segundo $1 / 2=0,50$, o terceiro $1 / 3=0,33$, o quarto $1 / 4=0,25$ e 0 quinto $1 / 5=0,20$, ou seja, o item que foi mencionado primeiro com peso 1 é o fator que mais incomoda o colaborador na realização de suas funções, priorizando assim os Itens de Demanda Ergonômica.

A partir dos resultados estabeleceu-se um ranking de insatisfação dos IDE'S de acordo com as menções das funcionárias, baseado na somatória das respostas que foram base para a elaboração do questionário, o que pode ser analisado no quadro a seguir.

Quadro 1- Resultados das entrevistas

\begin{tabular}{|c|c|c|c|}
\hline IDE'S & $\mathbf{1}$ & $\mathbf{2}$ & Total \\
\hline Falta de Espaço para Ateliê & 1,00 & & 1,00 \\
\hline Mesa de Corte & 0,50 & & 0,50 \\
\hline Sobrecarga de Funções & 0,33 & 0,50 & 0,83 \\
\hline
\end{tabular}




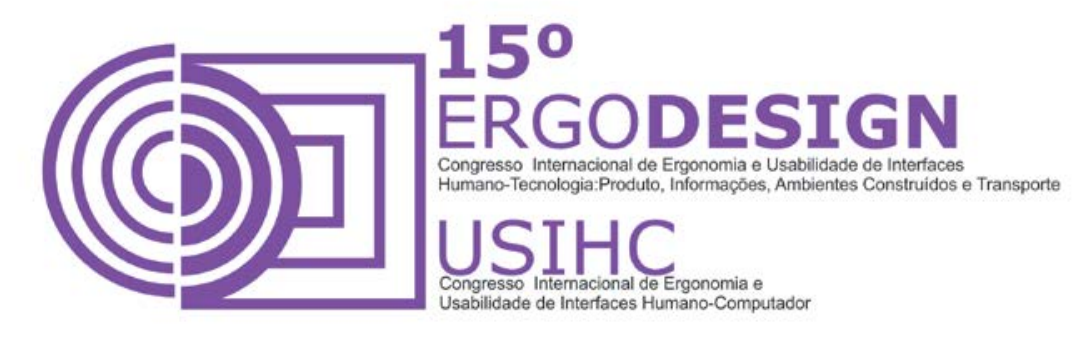

\begin{tabular}{|c|c|c|c|} 
Mesa e cadeira para Escritório & 0,25 & & 0,25 \\
\hline Falta de Tempo para Planejamento & 0,20 & & 0,20 \\
\hline Interrupções no momento de Criação & & 1,00 & 1,00 \\
\hline Imagens de inspiração para bordados & & 0,33 & 0,33 \\
\hline Tempo e gastos com atendimentos & & 0,25 & 0,25 \\
\hline Horários exaustivos & & 0,20 & 0,20 \\
\hline
\end{tabular}

\subsubsection{Questionários}

Segundo Gil, (1978 apud MORAES; MONT'ALVÃO, 2003, p. 43) o questionário é um instrumento de investigação que tem como objetivo conhecer as opiniões, situações vivenciadas e as expectativas dos entrevistados.

Com base no ranking de satisfação dos IDE'S e na somatória das respostas foi elaborado um questionário com 9 questões, as quais possibilitam medir o nível de importância ou satisfação do colaborador em relação aos problemas mencionados.

Para tanto, usou-se uma escala de avaliação contínua de $15 \mathrm{~cm}$ com duas âncoras nas extremidades, que permite medir o grau de intensidade de cada resposta variando de 0 (insatisfeito) a 15 (satisfeito), modelo sugerido por Stone (1974).

Para uma das entrevistadas este modelo foi adaptado, tornando-o mais fácil de ser entendido, devido a complexidade da compreensão do modelo. Para facilitar, o 0 foi substituído por uma imagem de representação gráfica de uma mão com sinal de negativo e o 15 por uma de positivo.

Com base no método, foi aplicado o questionário às funcionárias entrevistadas possibilitando avaliar o grau de satisfação dada aos itens mencionados, obtendo um valor, resultado da média aritmética das respostas de cada questão.

As respostas foram tabuladas e a partir da análise foi criado um gráfico, no qual os resultados são apresentados em uma ordem crescente de satisfação, representados na Figura 7. 

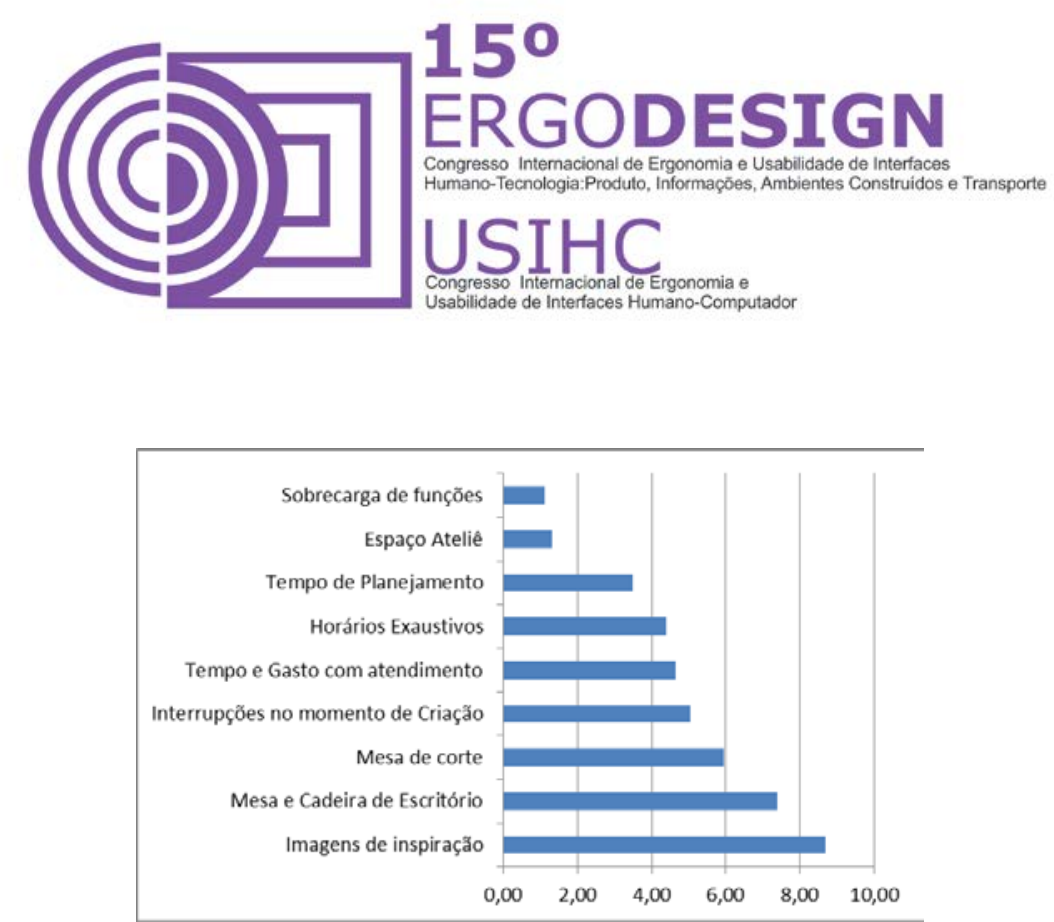

Figura 6- Gráfico de satisfação do resultado dos questionários.

Os IDE's considerados com maiores graus de insatisfação foram a sobrecarga de funções, o espaço para Ateliê, planejamento, horários exaustivos, tempo e gastos com atendimentos, interrupções no momento de criação, mesa de corte, falta de mesa e cadeira para escritório e disponibilização de imagens de inspiração para os bordados.

A empresa em um ano de funcionamento evoluiu e, consequentemente, houve um aumento de funções e produção, porém, o número de funcionários continua o mesmo, o que implica numa sobrecarga de tarefas e a falta de planejamento devido ao pouco tempo para execução. Portanto, muitas vezes funções que necessitam de precisão e atenção como, por exemplo, os bordados manuais, são realizados em horários exaustivos, na maioria das vezes no período da noite.

A carência de funcionários também implica em interrupções no momento de criação por representantes, telefones e mensagens. A falta de tempo e organização do trabalho interfere na disponibilização impressa das pesquisas de imagens de inspiração para os bordados para a funcionária que realiza essa função e não tem acesso ao computador.

A falta de espaço para o Ateliê foi relatado pelo fato dos equipamentos de trabalho não ficarem concentrados num mesmo lugar e dessa forma não há uma organização dos tecidos, aviamentos, pedrarias e etc. Também foi relatado que a altura da mesa de corte causa dores nas costas e a cadeira e mesa de apoio para notebook não são adequadas para esse uso. "Se a área de trabalho é muito baixa, as costas são sobrecarregadas pelo excesso de curvatura do tronco, o que dá frequentemente margem a queixas de dores nas costas" (GRANDJEAN, 1998, p.46).

A empresa oferece o serviço de atendimento a domicílio para o conforto do cliente, sendo também uma vantagem competitiva, no entanto, exige um tempo maior e gasto com combustível, visto que, algumas vezes é preciso ir de 2 a 4 vezes no mesmo endereço.

Estes são os itens com maior grau de insatisfação os quais foram considerados prioridades de projetos por sua ordem e frequência de menção. Portanto, as melhorias a serem sugeridas e posteriormente aplicadas referem-se aos mesmos. 


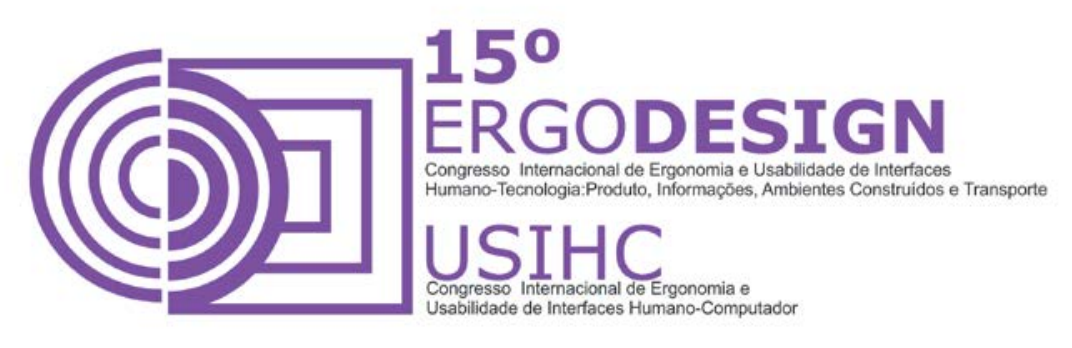

\subsection{Projetação Macroergonômica}

Foram geradas sugestões de melhorias aos IDE's mencionados, a fim de solucionar os devidos problemas prioritariamente.

\section{SOBRECARGA DE FUNÇÕES}

Para que as tarefas sejam executadas com eficácia, deve haver uma subdivisão de funções de acordo com as habilidades de cada funcionário, pois "A atividade profissional pode trazer prazer $e$ satisfação em graus muito diversos, que variam de acordo com a tarefa executada" (MORAES; MONT'ALVÃO, 2000, p.30).

Sendo assim, a solução proposta é que seja contratado um ou dois funcionários novos para diminuir essa sobrecarga ou a terceirização de alguns serviços como design gráfico, mídias digitais, marketing geral e serviços contábeis. Dessa forma, as tarefas das duas principais funcionárias ficariam concentradas no planejamento e desenvolvimento de produtos e na sua comercialização, diminuindo a sobrecarga de estresse no ambiente de trabalho. Conforme Grandjean (1998, p.165), "O estado emocional, causado por uma discrepância entre o grau de exigência do trabalho e os recursos disponíveis para gerenciá-lo, define o estresse do trabalho".

\section{FALTA DE ESPAÇO ATELIÊ}

Sugere-se reorganizar os equipamentos de trabalho em uma única sala, o que propiciaria um melhor desempenho das tarefas, com acesso fácil à matéria-prima, otimizando o tempo de trabalho. $\mathrm{O}$ ideal seria que os equipamentos fossem separados por setor como um ateliê, por exemplo, um espaço da sala definiria o setor de modelagem e corte onde se concentraria os materiais necessários para execução desse trabalho, em outro, as máquinas de costura e os aviamentos separados e organizados e por fim um espaço com uma mesa adequada para realização de trabalhos como criação, financeiro, com os arquivos e materiais para o desenvolvimento apropriado das atividades.

Conforme Moraes e Mont'Alvão "as atividades implicadas no trabalho, seu ambiente físico e social, exercem sobre o trabalhador certo número de constrangimentos, exigindo-lhe gastos de naturezas diversas: físico, mental, emocional, afetivo - e acarretando, portanto, desgastes e custos para o indivíduo" (2000, p.30). Dessa forma o problema de deslocamento seria solucionado, assim como facilitaria na organização física e mental do trabalho.

\section{FALTA DE TEMPO PARA PLANEJAMENTO}

A falta de organização da empresa é consequência da falta de planejamento, portanto, deve haver um tempo para planejar e organizar o trabalho visando rendimento, direção e ordem para executar 


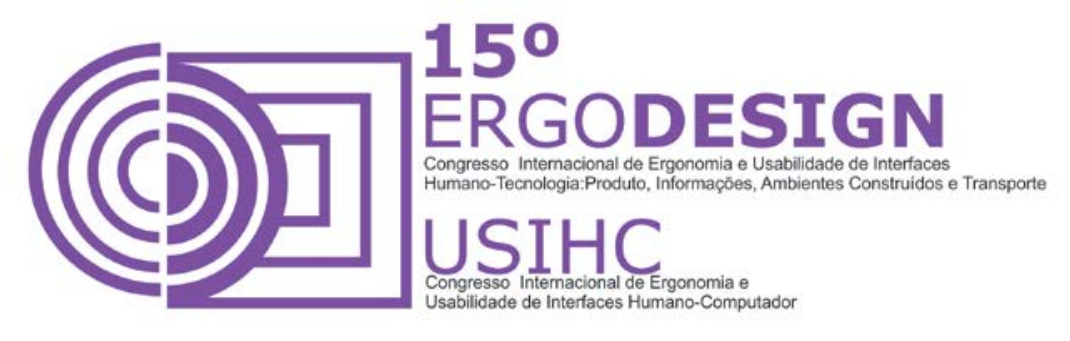

as funções. Este IDE está correlacionado a sobrecarga de funções, visto que, há muito trabalho a ser realizado, poucos funcionários para executar e, consequentemente, não há tempo para planejar as tarefas. A solução, após a diminuição da sobrecarga de funções por meio da terceirização ou contratação de novos funcionários, é construir um planejamento semestral ou anual de trabalho a ser comprido em relação ao desenvolvimento, produção, lançamentos, promoções e comercialização.

\section{HORÁRIOS EXAUSTIVOS}

Grandjean (1998, p.169) afirma que, "Nossos conhecimentos fisiológicos e as experiências até hoje acumuladas nos permitem concluir que uma jornada diária de 8 horas não pode ser ultrapassada sem que surjam danos pessoais, principalmente com trabalho intensivo". Como a jornada de trabalho é flexível, onde os trabalhadores podem começar ou terminar um trabalho livremente conforme sua vontade, há dificuldade de direção de trabalho e de manter a disciplina e a ordem.

O ideal é uma jornada flexível de trabalho onde haja um tempo de trabalho fixo e um tempo flexível, em que os horários são adaptados conforme a necessidade pessoal e ao ritmo biológico individual, dando autonomia ao trabalhador (GRANDJEAN, 1998). Cada colaborador pode definir um horário do dia como tempo fixo de acordo com sua necessidade e nesse período realizar as principais tarefas, principalmente as que exigirem maior concentração e precisão.

\section{TEMPO E GASTOS COM ATENDIMENTOS}

A recomendação em relação ao tempo e o gasto exigido com o atendimento a domicilio é que seja reservado um ou dois dias na semana exclusivamente para esse serviço, e ao invés de deixar o condicional para o cliente olhar e experimentar posteriormente, o atendimento seria como é feito dentro da loja ou showroom, de modo que o cliente tome a decisão de compra imediato, pois assim evitaria a necessidade da vendedora ir e vir mais de uma vez ao endereço, proporcionando conforto ao cliente por não ter que se deslocar até a loja.

\section{INTERRUPÇÕES NO MOMENTO DE CRIAÇÃO}

Sugere-se organizar as funções estabelecidas e adequar ao melhor horário para a sua execução. Tarefas que exigem concentração devem ser feitas em horários em que há pouca movimentação e interrupção no ambiente de trabalho. Organizar o tempo e programar atendimentos solucionaria parte do problema. Caso não seja suficiente, o ideal seria contratar uma secretária que ficaria responsável para atender telefones, responder e-mails, agendar atendimentos e etc.

\section{MESA DE CORTE}




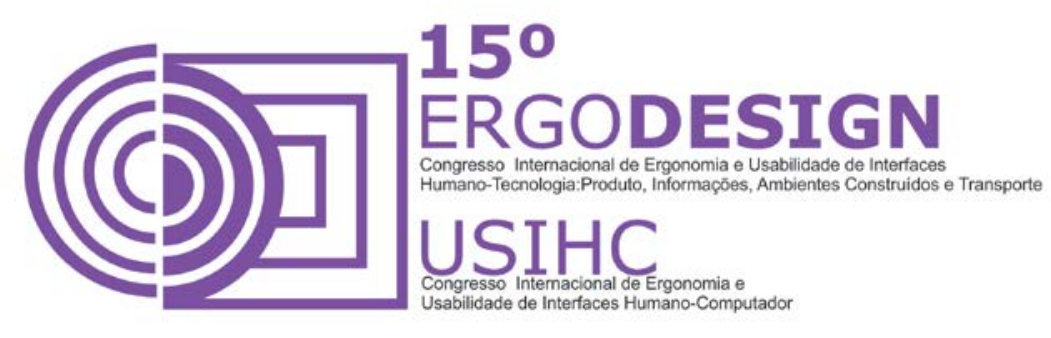

Para realizar um trabalho eficiente, é imprescindível a adaptação do local de trabalho às medidas do corpo humano (GRANDJEAN, 1998). Deste modo, observou-se que há a necessidade de adaptação ou uma nova mesa de corte na altura correta do funcionário que realiza esse serviço, para diminuir o excesso de curvatura do tronco, evitando dores nas costas.

É recomendada a altura de 5 a $10 \mathrm{~cm}$ abaixo da altura dos cotovelos para trabalhos manuais realizados em pé. Em média, a altura dos cotovelos (distância chão até o lado inferior do cotovelo dobrado em ângulo reto, com o braço na posição vertical) é de $105 \mathrm{~cm}$ nos homens e $98 \mathrm{~cm}$ na mulher. Portanto, pode-se deduzir que a altura média que a mesa necessita ter é entre 95 a $100 \mathrm{~cm}$ para os homens e entre 88 a $93 \mathrm{~cm}$ para as mulheres (GRANDJEAN,1998).

Se houver a necessidade de solução improvisada pode ser usado estrados para os pés ou aumento das pernas da mesa. O recomendável é que a altura da mesa seja regulável.

\section{MESA E CADEIRA PARA ESCRITÓRIO}

Para que o usuário tenha uma postura confortável e adequada para sua ocupação específica, é sugerida a compra de uma mesa e cadeira para a realização de trabalhos de escritório. Estas deverão possuir um espaço suficiente para as pernas de no mínimo $68 \mathrm{~cm}$ de largura e $68 \mathrm{~cm}$ de altura, possibilitando o cruzamento de uma por cima da outra (GRANDJEAN, 1998).

A posição relaxada e confortável do tronco é a prioridade dos empregados do escritório. Para tanto, a distância entre o assento e a superfície da mesa deve ficar entre 27 e $30 \mathrm{~cm}$. "Uma leve inclinação do tronco para frente, com os braços apoiados na mesa é seguramente uma postura pouco cansativa para ler ou escrever" (GRANDJEAN, 1998, p.51).

Considerando os aspectos ergonômicos, médicos e ortopédicos, para uma poltrona de descanso, o encosto deve ter uma altura de 48 a $52 \mathrm{~cm}$ acima do assento (na perpendicular), a largura entre 32 a $36 \mathrm{~cm}$, uma faixa de inclinação encosto/assento de $105^{\circ}$ a $110^{\circ}$ e encosto/horizontal de $110^{\circ}$ a $130^{\circ}$ e também necessita de uma almofada lombar situada a uma altura perpendicular de 10 a 18 $\mathrm{cm}$ do assento. A superfície do assento deve ter uma inclinação de $14^{\circ}$ a $24^{\circ}$ em relação à horizontal, para as nádegas não escorregarem para frente. Ele deve ter 40 a $45 \mathrm{~cm}$ de largura e 38 a $42 \mathrm{~cm}$ de profundidade. O estofamento deve ser com um material um pouco áspero que evite escorregar e impermeável ao vapor d'água, aumentando sensivelmente o conforto ao sentar (GRANDJEAN, 1998).

Contudo, uma cadeira de escritório necessita de uma graduação de altura entre 38 a 54 cm; assento giratório e borda frontal arredonda; 5 rodízios para permitir bom deslocamento na área de trabalho; boa resistência e segurança anti-emborcamento (GRANDJEAN, 1998). 

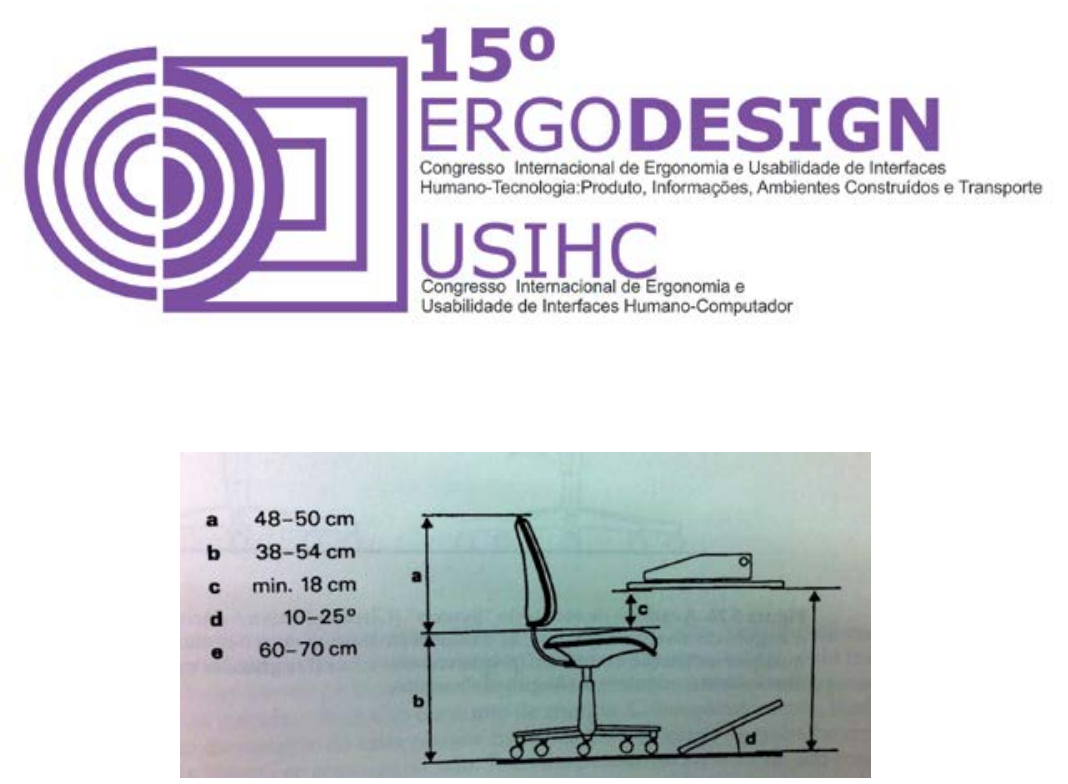

Figura 7- Medidas recomendadas para cadeira e mesa para trabalho em escritório (GRANDJEAN, 1998).

\section{IMAGENS DE INSPIRAÇÕES PARA BORDADOS}

Grandjean (1998) conclui que, para atividade mental no sentido lato, com maior exigência de criatividade, no geral, as informações devem ser cruzadas com conhecimentos técnicos já fornecidos para desenvolver estruturas mentais com certo valor novo, ou seja, formular novas ideias, portanto, em relação à disponibilidade de imagens de inspiração para o desenvolvimento e criação dos bordados, sugere-se que sejam selecionadas as principais referências do banco de dados virtuais que a empresa gera em cada coleção como fonte de inspiração e que as mesmas sejam impressas, gerando um arquivo manual para que a funcionária que realiza essa função tenha acesso fácil para consulta. Além de facilitar o trabalho e o acesso, reduziria o tempo de desenvolvimento do bordado.

\section{CONCLUSÃO}

Com a Análise Macroergonômica do Trabalho (AMT) na empresa de confecção observou-se a importância da participação das colaboradoras para a identificação dos IDE's significativos e a adequação do espaço físico às funções diárias de trabalho. Os problemas diagnosticados na pesquisa trazem consequências diversas como a insatisfação dos trabalhadores, queda de produtividade, problemas de saúde, bem como a falta de organização do trabalho.

No desenvolvimento da etapa de análise da percepção do ambiente pelos usuários houve facilidade para coleta de dados, pois as colaboradoras entenderam a necessidade de expor com clareza os problemas que enfrentam, mesmo sendo proprietárias da empresa.

Dessa forma, foi concluído que há a necessidade de modificações no processo laboral focado na melhoria das condições de trabalho, que irão influenciar diretamente na otimização do sistema produtivo. As mudanças sugeridas foram focadas nas reais necessidades particulares da empresa sob a visão exata de quem vive no ambiente analisado e, portanto, serão efetivas para melhorar a qualidade do trabalho destes funcionários.

\section{REFERÊNCIAS BIBLIOGRÁFICAS}

BUGLIANI, Raquel de Oliveira. Macroergonomia: um panorama do cenário brasileiro. Bauru, 2007. Dissertação (Mestrado em Desenho Industrial) - FAAC - UNESP - Faculdade de Arquitetura, Artes e 


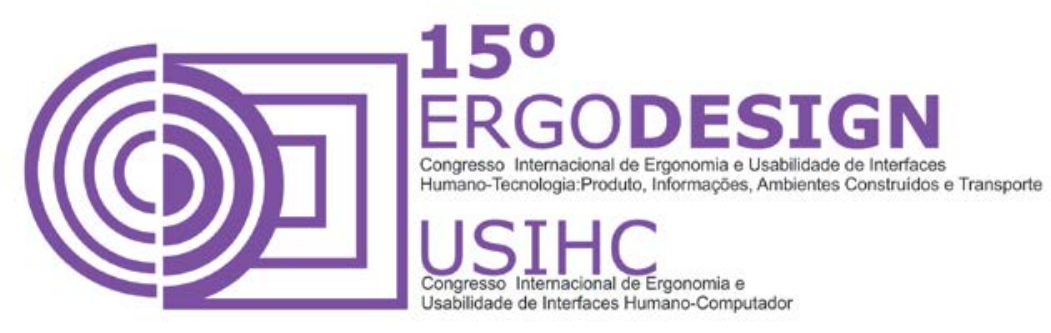

Comunicação da Universidade Estadual Paulista "Júlio de Mesquita Filho" - Campus Bauru.

FRANCO, Gesli. Vestuário é o novo trunfo paranaense. Disponível em: <http://www.gazetadopovo.com.br/economia/conteudo.phtml?id=1463360> . Acesso em: 25 jun. 2014.

GEPROS: Gestão da produção, operações e sistemas, Bauru, n. 2, 2006. Disponível em: <http://revista.feb.unesp.br/index.php/gepros/article/view/147/109>. Acesso em: 25 jun. 2014.

GONÇALVES, E.; LOPES, L. D. Ergonomia no vestuário: conceito de conforto como valor agregado ao produto de moda. In: ENCONTRO DE LATINO AMERICANO DE DESENHO EM PALERMO, 2., Argentina, 2007. Anais eletrônico... <http://fido.palermo.edu/servicios_dyc/encuentro2007/02_auspicios_publicaciones/actas_diseno/articulos _pdf/A039.pdf>. Acesso em: 20 jun. 2014.

GRANDJEAN, Etienne. Manual de ergonomia: adaptando o trabalho ao homem. trad. João Pedro Stein. Porto Alegre: Artes Médicas, 1998.

IIDA, Itiro. Ergonomia: projeto e produção. 2.ed.São Paulo: E. Blücher, 2005.

MORAES, Anamaria de; MONT'ALVÃO, Cláudia. Ergonomia: conceitos e aplicações. 2.ed. Rio de Janeiro: $2 A B, 2000$.

RECH, Sandra Regina. Moda: por um fio de qualidade. Florianópolis: Udesc, 2002.

ZERBETTO, Cristiane A. de A.; CARVALHO, Giovana G.; SILVA, Maria Antônia R.; ALEXANDRE, Monique dos S.; CREPALDI, Renata N.; BUSO, Vanessa Z. Uso do método da AMT no setor de pilotagem de uma indústria de confecção de vestuário. In: ERGODESIGN, 11, 2011, Curitiba. Anais... Curitiba: ERGODESIGN, 2011.

ZERBETTO, Cristiane A. de A.; VIEIRA, Alexandre J. F; FERREIRA, João; JORGE, Lívia S.; BARBOSA, Thuany. Diagnóstico macroergonômico do setor de polimento de uma indústria moveleira. In: ERGODESIGN, 11, 2011, Curitiba. Anais... Curitiba: ERGODESIGN, 2011. 